\title{
Simulation System of Technological Support of Automated Complex
}

\author{
A.V. Oleynik ${ }^{1}$, L.V. Kuznetsova ${ }^{1}$, A.V. Nikolaev $^{2}$, L.Yu. Kuznetsov ${ }^{3}$, M. Dimitrov ${ }^{2,4}$ \\ ${ }^{1}$ Moscow State Technological University "STANKIN", RU-127055, Moscow, Russia \\ ${ }^{2}$ Ulyanovsk Institute of Civil Aviation, RU-432071, Ulyanovsk, Russia \\ ${ }^{3}$ Mercedes-Benz / Mercedes-Benz Russia AO, RU-125167, Moscow, Russia \\ ${ }^{4}$ M.G. Dimitrov / E-Motion Life, BG-9010, Varna, Bulgaria
}

\begin{abstract}
Mathematical modeling of technical and technological systems and processes occurring in these systems can be interpreted as multi-step processes of solving managerial problems, where the application of classical methods for obtaining numerical results is possible. In particular, it is practical to apply the theory of dynamic programming based on the use of functional equations and the optimality principle to solve the problem of resource allocation. In the formulation and solution of the dynamic programming problem, the process is divided into stages in time, and at each stage decisions at which the goal is achieved are made. In our case, homogeneous stages are considered, and the use of the optimality principle leads to the fact that a decision made at each stage is the best regarding the entire process..
\end{abstract}

\section{Introduction}

In our case, the task was to equalize the load of production capacities when servicing automated equipment, namely, the production line. To do this, you need to make a series of decisions that depend on the actual production situation [1-5]. It should be noted that modern methods of enterprise equipment management in terms of equipment maintenance and repair can be as follows:

1. Maintenance according to the level of reliability, when the reliability of the equipment is a function of the design, workmanship and actions of personnel during maintenance and repair of equipment.

2. Risk control - optimizing the maintenance and repair of equipment based on an assessment of the risk of loss of performance. In this case, it is necessary to identify sources of risk - components of the main risk of loss of equipment operability.

3. Industrial maintenance is the maintenance of equipment that ensures its operability without breakdowns throughout the entire life cycle. At the same time, the work of all personnel ensuring the equipment life cycle is taken into account.

\section{Dynamic programming}

It is necessary to make decisions in real time based on relevant data. This is possible with dynamic programming [6-15]. Finding the optimal solutions is as follows: let $\mathrm{Yk}$ be the set of states from which in $\mathrm{k}$ steps one can get into one of the states of the final set of states of the production system $\mathrm{X} \mathrm{N}$.
We can assume that $\mathrm{Y} 0=\mathrm{X} \mathrm{N}$.

We take an arbitrary $\mathrm{xN}-\mathrm{k} \in \mathrm{Yk}$ and denote by Sk $(\mathrm{Xn}-\mathrm{k})$ the function that describes the dependence of the optimal work distributions over time on the state $\mathrm{xN}$ $-\mathrm{k}$ in $\mathrm{k}$ last steps that take the system from $\mathrm{xN}-\mathrm{k}$ to $\mathrm{X}$ $\mathrm{N}$.

Since for states $\mathrm{xN}-1$ from the set $\mathrm{Y} 1$ the transition to $\mathrm{XN}$ takes place in one step, the function of optimal distributions of jobs $\mathrm{S} 1(\mathrm{xN}-1)$ can be written as follows:

$\mathrm{S} 1(\mathrm{xN}-1)=\min \{\mathrm{dN}(\mathrm{xN}-1, \mathrm{uN})\}$

$\mathrm{uN} \in \mathrm{UN}(\mathrm{xN}-1)$

$\mathrm{fN}(\mathrm{xN}-1, \mathrm{uN}) \in \mathrm{X} \mathrm{N}$

The second restriction is necessary in order to guarantee the achievement of a given final set $\mathrm{X} \mathrm{N}$.

The value of $\mathrm{uN}$ at which a minimum is reached in this ratio is denoted by $\mathrm{u}^{*} \mathrm{~N}(\mathrm{xN}-1)$. Then the function of optimal distributions of the jobs Sk $+1(\mathrm{xN}-\mathrm{k}-1)$ of each next problem is expressed recursively in terms of the previous $\mathrm{Sk}(\mathrm{xN}-\mathrm{k})$

$\mathrm{Sk}+1(\mathrm{xN}-\mathrm{k}-1)=\min \{\mathrm{dN}-\mathrm{k}(\mathrm{xN}-\mathrm{k}-1, \mathrm{uN}-\mathrm{k})+\mathrm{Sk}$ $(\mathrm{fN}-\mathrm{k}(\mathrm{xN}-\mathrm{k}-1, \mathrm{uN}-\mathrm{k}))\}$

$\mathrm{u}^{*} \mathrm{~N}-\mathrm{k}(\mathrm{xN}-\mathrm{k}-1)-$ management at which a minimum of work distributions is achieved in (2)

The expression $\mathrm{u} * \mathrm{k}$ (xk-1) defines the optimal control rules for each moment of time in the form of functions of the current state of the dynamic process, sets the law of optimal control over the distribution of work.

e-mail: vv2@bk.ru 
The optimal initial state $\mathrm{x}^{*} 0$ can be obtained from the solution of the following problem:

$\mathrm{x}^{*} 0=\operatorname{argmin}(\mathrm{SN}(\mathrm{x} 0), \mathrm{x} 0 \in \mathrm{X} 0)$

The solution of the system of equations (1)-(3), called Bellman's recurrent equations, was taken as the basis for the development of a software package for planning and distribution of equipment maintenance and repair work, which made it possible to optimize the loading of facilities for servicing automated equipment, namely, the production line. At the same time, the resulting software solution can be integrated into the module for maintenance and repair of equipment implemented in the mySAP ERP enterprise resource planning computer system.

The general scheme of the equipment maintenance and repair module in mySAP ERP includes the following organizational elements:

1.Plant for the location of technical objects (Maintenance plant). This may be a production or workshop where there is equipment that needs to be maintained and repaired;

2. Maintenance work centers - units, sections, brigades or individuals who perform maintenance and repair work on equipment.

3. Spare part warehouse (Warehouse) - a unit of the plant that is engaged in the storage and accounting of spare parts for the maintenance and repair of equipment. Maintenance work centers belong to the mySAP ERP master data and provide the capacity needed to carry out a specific repair or maintenance task.

Equalization of capacity utilization, based on Bellman's recurrence equations, is carried out by moving orders for preventive maintenance from weeks with high load to weeks with less load.

Weekly load is calculated for a specific workplace:

- Available capacity (AC) - available working time for a specific workplace. It is measured in hours, minutes. Equally the calendar duration per week minus weekends, holidays, non-working time and break time (for example, for a week with two non-working days, with the beginning and end of working time from 08:00 a.m. to 05:00 p.m. and with a break of 1 hour, the available capacity will be 40 hours)

- Required capacity (RC). It is measured in hours, minutes. Equal to the sum of working time requirements for a particular workplace in all order operations.

- Work center load (WCL). Measured in percent. Equal to the ratio of the need for working time from all operations of all orders for the week to the available capacity of the workplace for the same week. WCL = RC / AC * $100 \%$

The coefficient for overloaded weeks / Overloaded capacity coefficient varies in the range: from 0.75 to 1.25 and determines the limit of deviation from the average load, when hit in which the week is not considered overloaded.

The coefficient for underutilized weeks / Unutilized capacity coefficient varies from: 0.75 to 1.25 , and determines the deviation from the average load, after which orders stop moving in this week
Alignment Mode Algorithm:

Weekly Download Data

01. For the workplace, we calculate the workload for each week related to the analysis period,

02. Calculate the load of equipment for each week,

03. Calculate the total overload and underload factors as the sum of the corresponding weekly values,

04. Calculate the average weekly load,

05. Define weeks containing excess capacity (weeks from which orders must be moved),

06. For the weeks found in the previous pp, we determine the excess power (the amount of power that needs to be moved),

07. We determine the weeks in which it is necessary to move orders,

08. For the weeks found in the previous paragraphs, we determine the missing capacity (the amount of power that needs to be moved).

Order Data:

01. Make a selection of orders according to the criteria:

- Plant,

- Type of order,

- Orders with active statuses are excluded,

- The base start dates are within the analysis period,

- We exclude orders having operations with the workplace

- We determine the maximum displacement horizon - the number of weeks by which the order can be shifted for a certain periodicity of scheduled preventive repairs. The actual shift of the order date cannot go beyond the analysis period interval.

02. For found orders, we define:

- Necessary power for the workplace.

- Station affiliation: orders that have the same value for this field apply to one station / line.

Moving orders grouped by station

01. Group orders. Orders belong to the same group if they belong to the same periodicity group, to one calendar week and to one station. For each group, the total required power is found.

02. Groups of orders with the highest frequency of technical maintenance (MOT) are selected, then a group with the highest required capacity is selected from them. Orders from this group are moved on the first working day of the week with the largest deficit (highest Missing capacity) within the offset horizon. If the volume of transferred capacity exceeds the deficit of the target week (Missing capacity) taking into account already moved orders or the excess capacity of the moved week (Missing capacity) taking into account already moved orders, only part of the orders from the group are moved. The remaining orders belonging to this group are transferred outside the scope of the movement of orders grouped by station.

03. The previous step is repeated for a group with less power needed. When all order groups within the selected maintenance interval are moved, orders are moved from groups with a lower maintenance interval. And so on until the last possible group of orders is moved. 
Moving orders not grouped by station

It is executed after moving orders grouped by stations.

01. Orders are moved first with the maximum frequency of service, starting with orders with the maximum power requirement, starting with the week with the maximum load that remains to be moved from it.

Moving is performed on the first working day of the week with the highest Missing capacity, taking into account already moved orders.

The need for the working time of the moved order should not exceed the excess capacity (Capacity surplus) of the week from which the transfer is made, minus the already moved capacity.

02. When all orders within the selected maintenance interval are moved, orders are moved with a lower maintenance interval. And so on until the last possible order is moved.

Maintenance Work centers are used in other structural elements of mySAP ERP:

- in the master record of a unit of equipment (or technical location), it will be indicated who will carry out repairs and maintenance, therefore there is an indication of the PMO Workstation;

- in the header of the routing and for maintenance and repair operations should indicate who performs the work - Maintenance Workplace;

- the list of preventive maintenance and repair work performed for each item indicates the Maintenance Workplace;

- the heading of the order and the order for maintenance and repair should also indicate Maintenance Workstations.

In mySAP ERP, for the purpose of describing and structuring production systems to be maintained and repaired, there are four types of software engineering objects:

- Technical places (Functional location)

- Pieces of equipment

- Bills of Material

- Serial numbers

Functional location is an element of a multi-level hierarchical technical structure in which an object can be installed (for example, a piece of equipment).

Technical spaces are created when necessary:

- structure the technical system according to the functional criterion;

- record maintenance and repair work for certain sections of the technical system;

- keep technical data for a long time;

- provide control over the costs of maintenance and repair for certain sections of the technical system;

- analyze the impact of operating conditions on the likelihood of damage to mounted items of equipment.

A piece of equipment is a separate physical object that is subject to maintenance and repair as a separate unit.

The unit of equipment is unique and for it you can perform the following actions:

- register maintenance activities;

- account for maintenance costs;
- record time of use;

- enter individual data;

- keep technical data for a long time.

A piece of equipment can be associated with Material to manage inventory in a warehouse. The material specification in the maintenance differs from other specifications in that it contains only those items that are necessary for the maintenance and repair of equipment.

Thus, the addition of the module for maintenance and repair of mySAP ERP equipment with calculations that make it possible to equalize the load of production capacities by modeling the technological support system for the operability of automated equipment, significantly expanded the functionality of this module.

\section{Conclusion}

The software package as part of mySAP ERP, called "Automatic change of order dates for scheduled preventive maintenance with the aim of evenly distributing workloads", was praised by specialists and management of Mercedes-Benz RUS, a company within Daimler AG. In the future, it is planned to introduce the program complex "Automatic change of dates of orders for PPR for the purpose of uniform distribution of workload loading” at the Automobile Plant GAZ (Nizhny Novgorod).

This work was carried out using equipment provided by the Center of Collective Use of MSUT "STANKIN".

\section{References}

1. PLM300 Business Processes in Maintenance and Repair. Guide for Course Participants (SAP AG, 2005)

2. TERP10 Integration of mySAP ERP Business Processes (SAP AG, 2006)

3. I.I. Kosenko, L.V. Kuznetsova, A.V. Nikolaev, L.Yu. Kuznetsov, A.V. Oleinik Modeling and Virtual prototyping. (Technological service) (Master: Textbook. - M.: Alpha-M: INFRA-M, 2016)

4. R. Miller, Sequential and Parallel Algorithms: General Approach / R. Miller, L. Boxer; trans. from English (M.: BINOM. Laboratory of Knowledge, 2006)

5. S.N. Grigoriev, M.P. Kozochkin, F.S. Sabirov, and A.A. Kutin, Proc. CIRP, 1, 599-604 (2012)

6. S.N. Grigoriev, V.D. Gurin, M.A. Volosova, and N.Y. Cherkasova, Materialwiss. Werkstofftech., 44(9), 790-796 (2013)

7. S.N. Grigoriev, G.M. Martinov, Proc. CIRP, 41, 858-863 (2016)

8. S.N. Grigoriev, G.M. Martinov, Proc. CIRP, 14, 517-522 (2014)

9. A.V. Oleynik, L.V. Kuznetsova, V.E. Petrov, 2018 Proc. Int. Conf. "Quality Management, Transport and Information Security, 
Information Technologies", IT and QM and IS, 704-708 (2018)

10. A.G. Ivakhnenko, V.V. Kuts, O.Y. Erenkov, E.O. Ivakhnenko, A.V. Oleinik, Russian Engineering Research 37(10), 901-905 (2017)

11. X. Jiang, W. Xiong, L. Wang, M. Guo \& Z. Ding Heat treatment effects on microstructure-residual stress for selective laser melting AlSi10Mg, Mat. Sci. and Tech., (2019) DOI: $10.1080 / 02670836.2019 .1685770$

12. E. Semenishchev et al. Algorithm for image stitching in the infrared //Infrared Tech. and Appl. XLV. Int. Soc. for Optics and Photonics, 11002, P.110022 (2019).

13. S.N. Grigoriev, V.A. Sinopalnikov, M.V. Tereshin, and V.D. Gurin, Measur. Techn., 55(5), 555-558 (2012)

14. E.A. Semenishchev et al. Stitching algorithm of the images acquired from different points of fixation //Digital Photography XI. International Society for Optics and Photonics, 9404, P. 94040R, (2015).

15. E. Semenishchev, V. Marchuk, I. Shrafel, V. Dubovskov, T. Onoyko \& S. Maslennikov, In Mobile Multimedia, Image Processing, Security, and Applications 9868, 98690E (2016)

16. V.V. Voronin, R. Sizyakin, I. Svirin, A. Zelensky, A. Nadykto, SPIE-Intl Soc Optical Eng in Counterterrorism, Crime Fighting, Forensics, and Surveillance Technologies II 10802; (2018) doi:10.1117/12.2326806

17. E. Semenishchev; V. Voronin.; A. Zelensky; I. Shraifel, Infrared technology and applications XLV 11002 (2019) DOI: 10.1117/12.2519537 